Supplement of Biogeosciences, 18, 3657-3687, 2021 https://doi.org/10.5194/bg-18-3657-2021-supplement (C) Author(s) 2021. CC BY 4.0 License.

(c) (1)

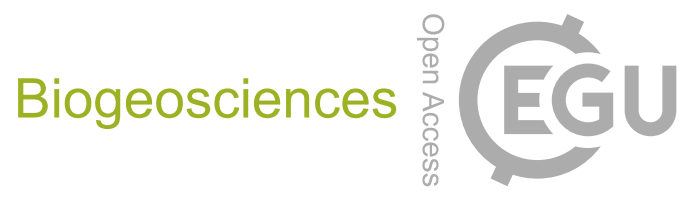

Supplement of

\title{
Committed and projected future changes in global peatlands - continued transient model simulations since the Last Glacial Maximum
}

Jurek Müller and Fortunat Joos

Correspondence to: Jurek Müller (jurek.mueller@climate.unibe.ch)

The copyright of individual parts of the supplement might differ from the article licence. 


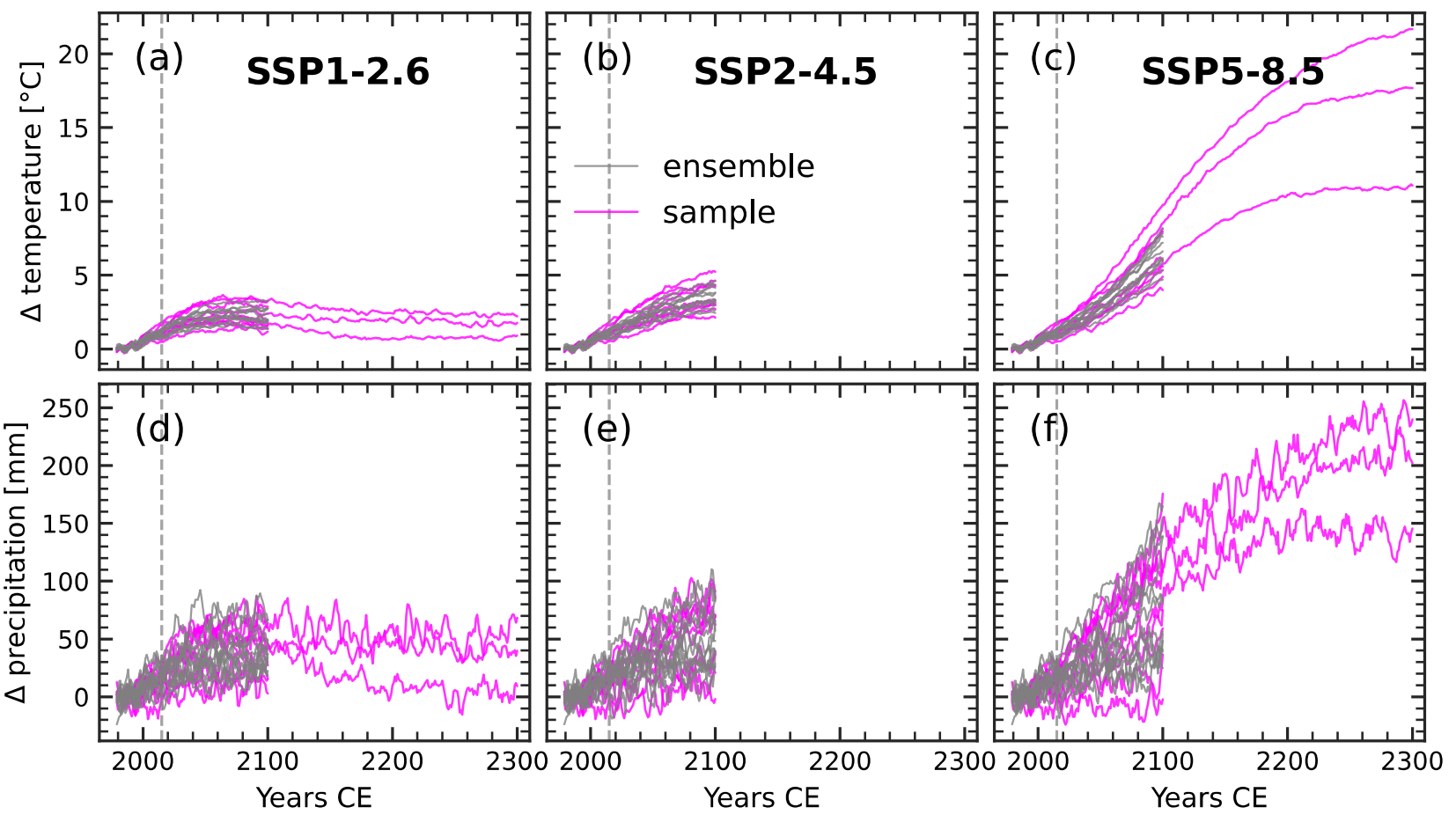

Figure S1:

Global temperature (a-c) and precipitation (d-f) anomalies to the 1961-1990 average for three CMIP6 scenarios: SSP1-2.6 (a,d), SSP2-4.5 (b,e), SSP5-8.5 (c,f) and extended SSP1-2.6 and SSP58.5 for three models. Mangenta lines show anomalies of the climate model sample versus the rest of the CMIP6 ensemble in grey. Dashed vertical gray lines show the year 2015 from which the future scenarios diverge 


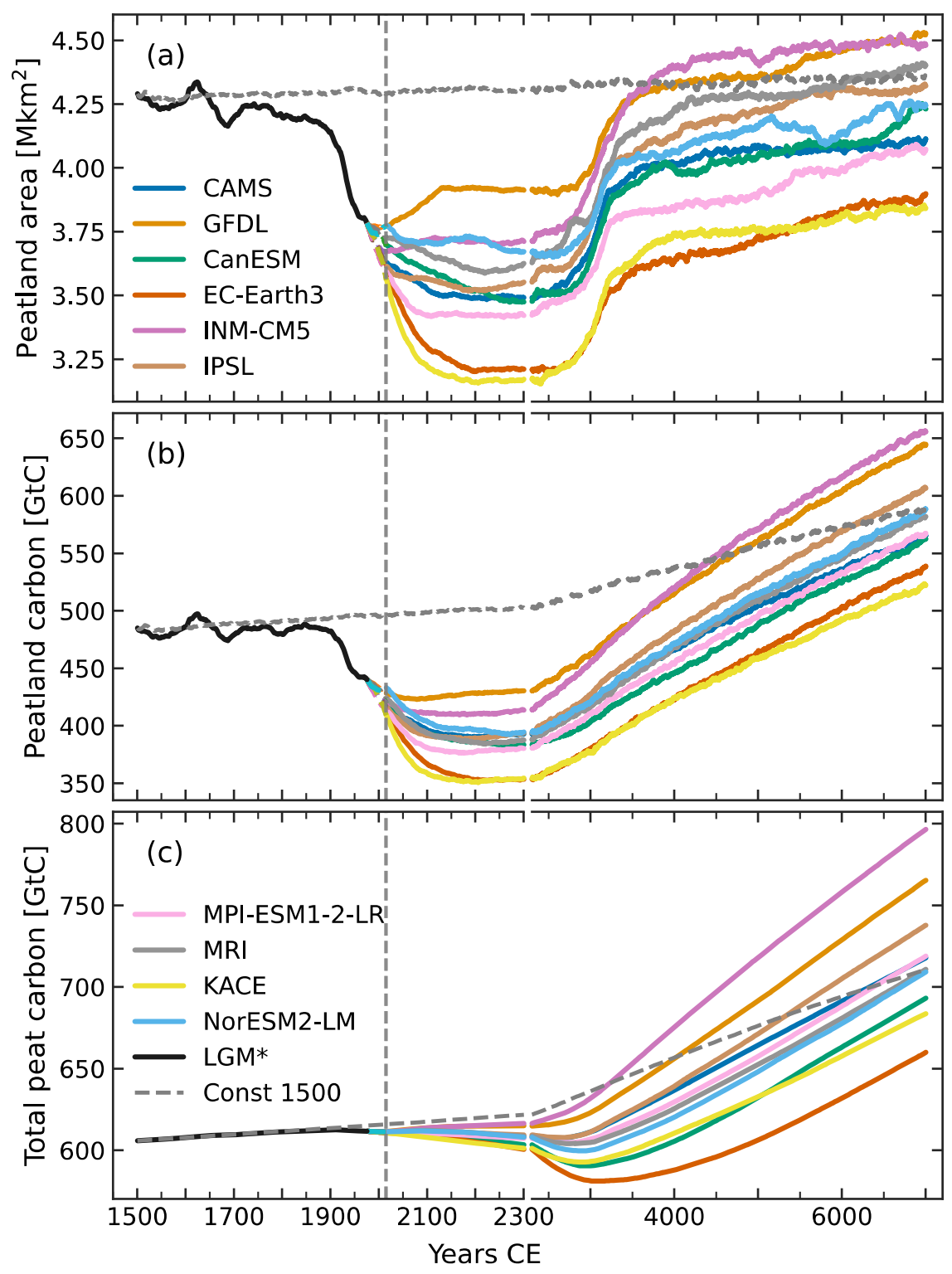

Figure S2:

Simulated continued transient evolution after the LGM run (LGM*) of (a) global peatland area, (b) global peatland carbon, and (c) global total peat carbon under under constant 1500 and 2014 conditions. Shown are ten simulations forced with different climate model anomalies. The dashed vertical line indicates the year 2014. Note the change in the time axis after the year 2300 

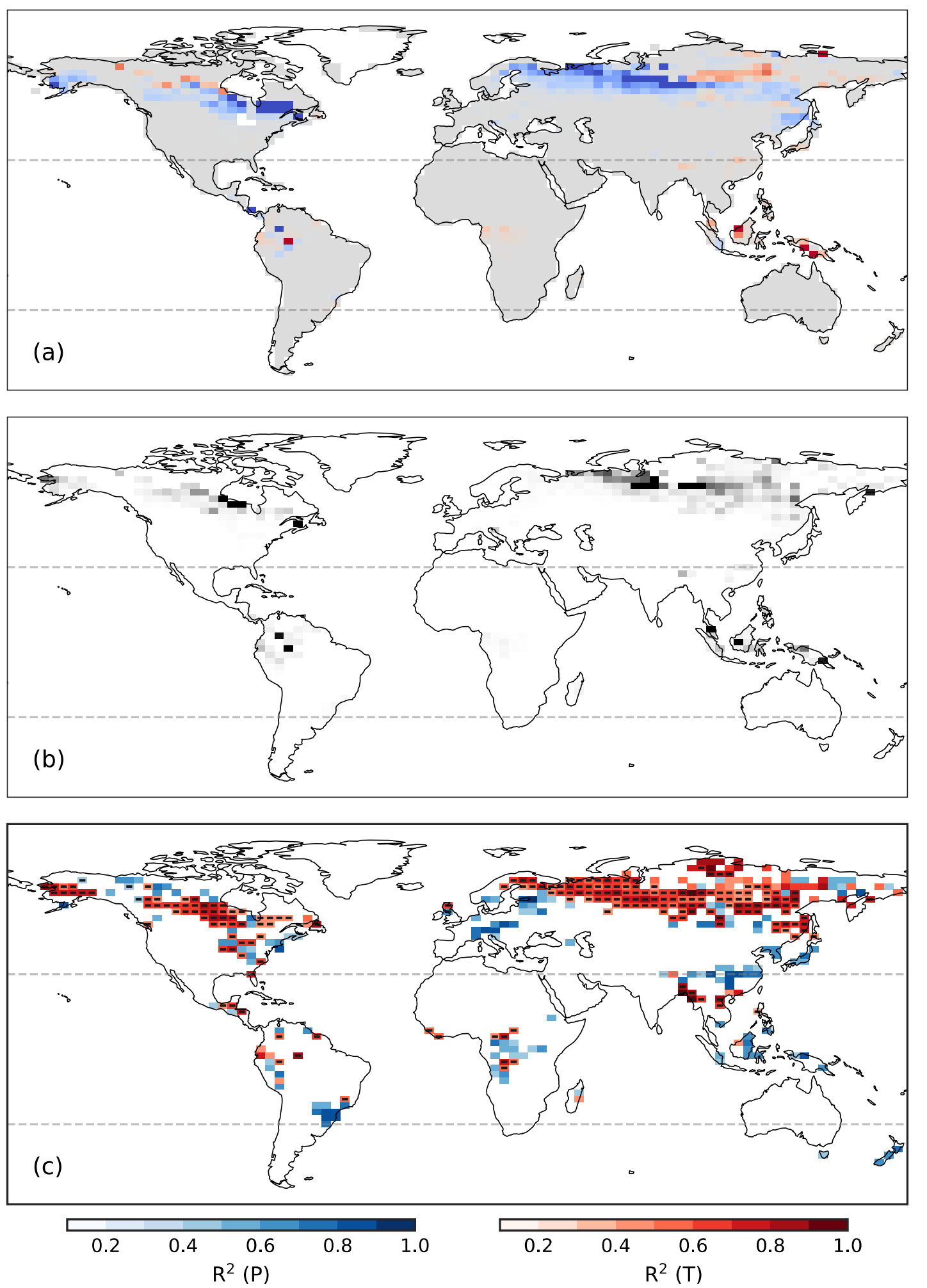

Figure S3:

Year 2300 SSP2-4.5 peatland area fraction anomaly (a) median, (b) inter quartile range and (c) squared correlation coefficient $\left(\mathrm{R}^{2}\right)$ for a linear regression between the ten different sample precipitation or temperature values and the resulting peatland fraction in the respective simulation. Plotted in (c) are only cells with significant correlation ( $>0.05)$. Color code in (c) denotes the dominant predictor in the respective cell. Cells with a negative regression slope are marked with a minus 

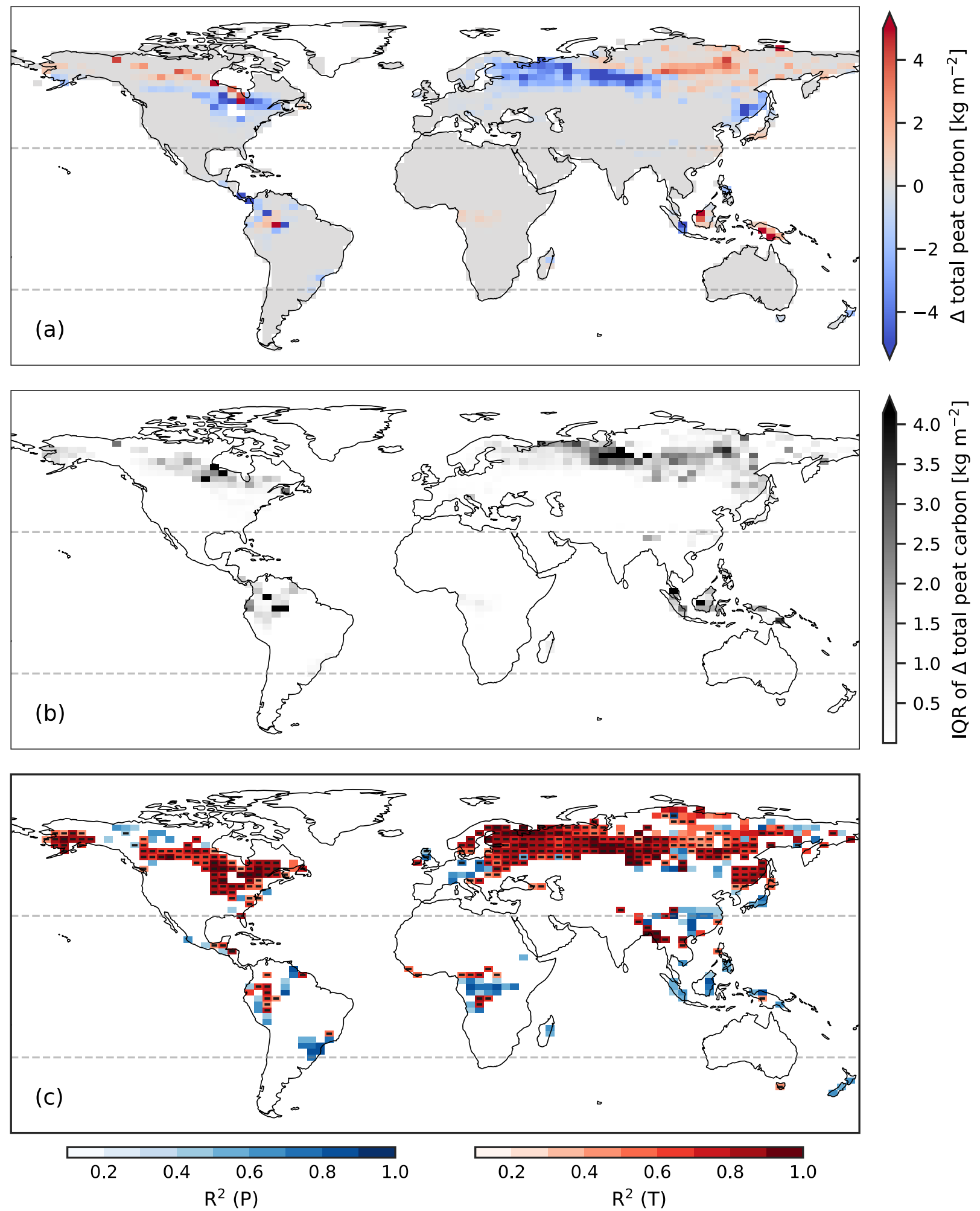

Figure S4:

Year 2300 SSP2-4.5 total peat carbon anomaly (a) median, (b) inter quartile range and (c) squared correlation coefficient $\left(\mathrm{R}^{2}\right)$ for a linear regression between the ten different sample precipitation or temperature values and the resulting total peat carbon concentrations in the respective simulation. Plotted in (c) are only cells with significant correlation ( $p>0.05$ ). Color code in (c) denotes the dominant predictor in the respective cell. Cells with a negative regression slope are marked with a minus 

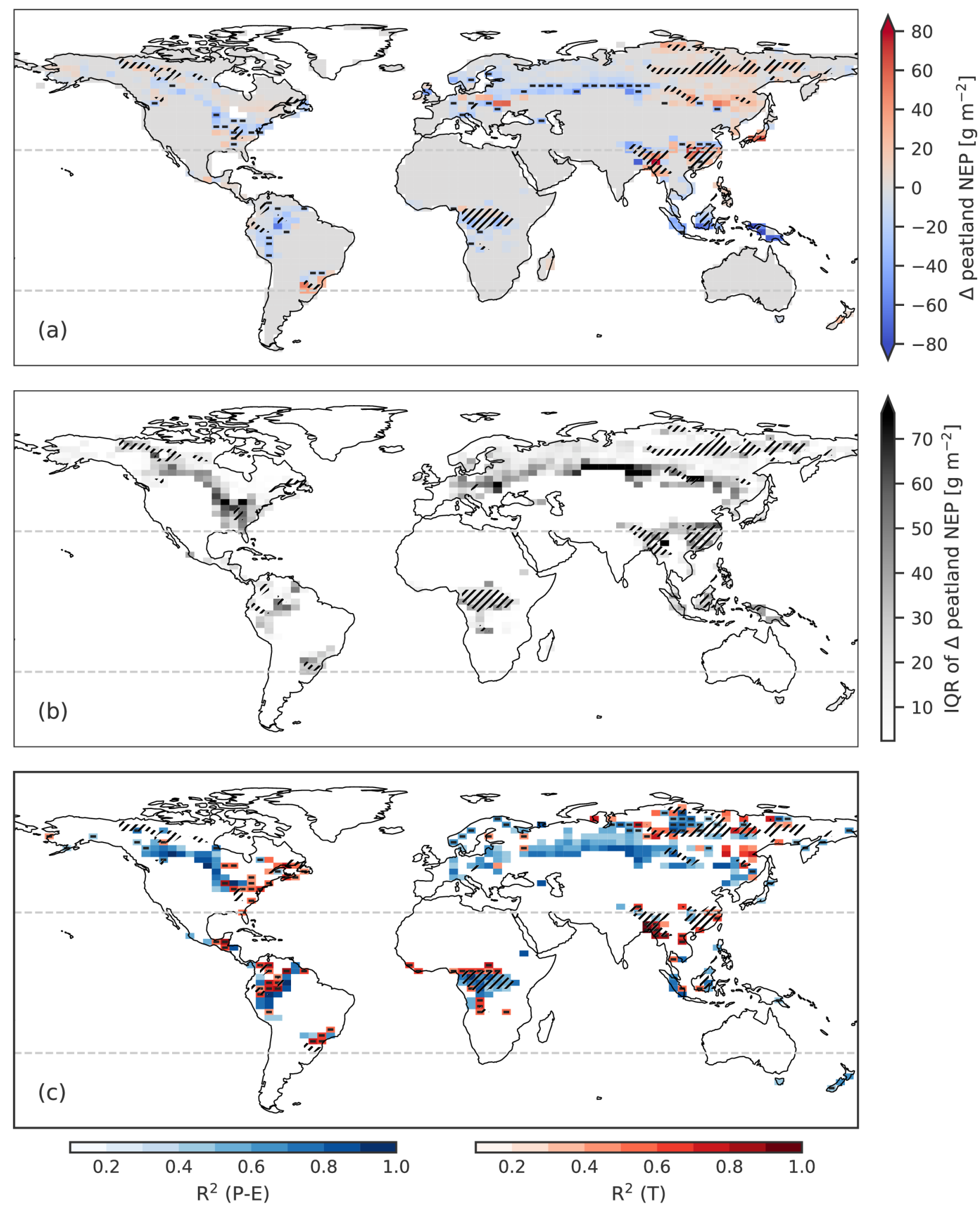

Figure S5:

Year 2300 SSP2-4.5 peatland NEP anomaly (a) median, (b) inter quartile range and (c) squared correlation coefficient $\left(\mathrm{R}^{2}\right)$ for a linear regression between the ten different sample precipitation or temperature values and the resulting peatland NEP in the respective simulation. Gridcells where NEP becomes negative are marked with a minus in (a). Plotted in (c) are only cells with significant correlation ( $p>0.05$ ). Color code in (c) denotes the dominant predictor in the respective cell. Cells with a negative regression slope are marked with a minus. Hatched areas indicate a positive area anomaly, which in the model can lead to an increase in NEP through the dilution of soil carbon 


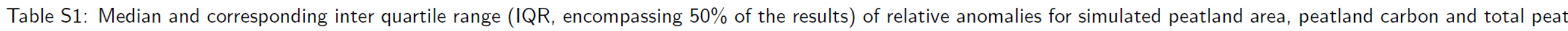

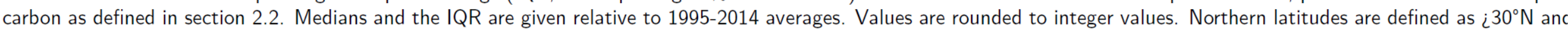

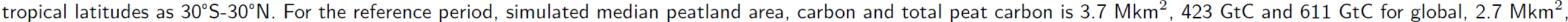
$301 \mathrm{GtC}$ and $500 \mathrm{GtC}$ for northern, and $1 \mathrm{Mkm}^{2}, 121 \mathrm{GtC}$ and $142 \mathrm{GtC}$ for tropical peatlands respectively

\begin{tabular}{|c|c|c|c|c|c|c|c|c|c|}
\hline & \multicolumn{3}{|c|}{$\Delta$ peatland area $[\%]$} & \multicolumn{3}{|c|}{$\Delta$ peatland carbon $[\%]$} & \multicolumn{3}{|c|}{$\Delta$ total peat carbon [\%] } \\
\hline & 2100 & 2300 & 3500 & 2100 & 2300 & 3500 & 2100 & 2300 & 3500 \\
\hline \multicolumn{10}{|l|}{ Global } \\
\hline Committed & $-3(-5--1)$ & $-4(-6--2)$ & $+8(+5-+10)$ & $-7(-9--6)$ & $-9(-10--7)$ & $+4(+1-+7)$ & $-0(-0-+0)$ & $-1(-1--0)$ & $+1(-1-+2)$ \\
\hline SSP1-2.6 & $-7(-10--5)$ & $-4(-13-+3)$ & $+16(-3-+20)$ & $-14(-18--10)$ & $-12(-26--5)$ & $+7(-15-+12)$ & $-0(-0-+0)$ & $-0(-2-+1)$ & $+3(-8-+6)$ \\
\hline SSP2-4.5 & $-11(-15--6)$ & $-23(-28--9)$ & $0(-12-+15)$ & $-19(-23--13)$ & $-33(-42--20)$ & $-17(-31-+0)$ & $-0(-1--0)$ & $-2(-5--1)$ & $-4(-17-+0)$ \\
\hline SSP5-8.5 & $-14(-17-8)$ & $-29(-33--21)$ & $-2(-11-+16)$ & $-22(-27--17)$ & $-43(-53--36)$ & $-29(-43--13)$ & $-1(-1--0)$ & $-5(-8--3)$ & $-17(-32--11)$ \\
\hline \multicolumn{10}{|l|}{ Northern } \\
\hline Committed & $-8(-9--5)$ & $-11(-14--8)$ & $-4(-6--1)$ & $-10(-12--8)$ & $-12(-15--11)$ & $-1(-4--0)$ & $+0(-0-+0)$ & $-0(-1--0)$ & $-0(-1-+1)$ \\
\hline SSP1-2.6 & $-15(-22--11)$ & $-18(-32--6)$ & $-8(-22-+3)$ & $-19(-26--16)$ & $-18(-38--8)$ & $-5(-28-+7)$ & $-0(-0-+0)$ & $-1(-2-+1)$ & $-2(-10-+4)$ \\
\hline SSP2-4.5 & $-22(-27--12)$ & $-41(-54--24)$ & $-31(-44--13)$ & $-26(-33--18)$ & $-47(-59--29)$ & $-37(-54--16)$ & $-0(-1-+0)$ & $-3(-5--1)$ & $-14(-25--6)$ \\
\hline SSP5-8.5 & $-28(-32--16)$ & $-61(-70--50)$ & $-54(-67--37)$ & $-32(-37--24)$ & $-65(-73--57)$ & $-61(-75--49)$ & $-1(-1--0)$ & $-7(-10--4)$ & $-32(-47--22)$ \\
\hline \multicolumn{10}{|l|}{ Tropical } \\
\hline Committed & $+9(+5-+11)$ & $+14(+9-+19)$ & $+37(+33-+41)$ & $-0(-2-+1)$ & $+2(-1-+4)$ & $+21(+16-+24)$ & $-0(-1-+0)$ & $-1(-1--0)$ & $+5(+3-+7)$ \\
\hline SSP1-2.6 & $+14(+8-+19)$ & $+27(+16-+36)$ & $+66(+46-+72)$ & $+2(-0-+2)$ & $+5(+0-+8)$ & $+32(+18-+39)$ & $+0(-0-+0)$ & $-0(-2-+2)$ & $+13(+4-+19)$ \\
\hline SSP2-4.5 & $+14(+8-+19)$ & $+34(+23-+38)$ & $+84(+71-+90)$ & $-1(-3--0)$ & $+2(+0-+6)$ & $+32(+25-+38)$ & $-1(-1-+0)$ & $-1(-3-+1)$ & $+13(+6-+16)$ \\
\hline SSP5-8.5 & $+19(+14-+22)$ & $+60(+42-+76)$ & $+143(+128-+158)$ & $-0(-2-+2)$ & $+7(+0-+13)$ & $+56(+32-+62)$ & $-1(-1--0)$ & $+1(-5-+4)$ & $+28(+6-+34)$ \\
\hline
\end{tabular}

